\title{
Biodiversity in the Anthropocene
}

\author{
David L. Pearson ${ }^{1}$ (1)
}

Received: 20 November 2019 / Accepted: 17 January 2020 / Published online: 25 January 2020

(c) Springer Nature Switzerland AG 2020

\begin{abstract}
Conservation efforts to maximize biodiversity cannot dwell on past methods and policies. Future biodiversity will involve large human populations, urbanization, and secondary habitats that will require major changes in emphasis, communication, and policy.
\end{abstract}

Keywords Anthropocene $\cdot$ Biodiversity $\cdot$ Citizen Science $\cdot$ Communication $\cdot$ Natural $\cdot$ Urbanization

When I was six years old, I met the last surviving Union soldier from the American Civil War, Albert Woolson. He told me that when he was my age, one of his relatives shared stories of his time fighting in the American Revolutionary War, in the late 1700s. In the short time span since then, our world's population has gone from less than a billion to almost 8 billion. Our children will likely see 10 to 12 billion people on the planet in their lifetimes (Bongaarts and O'Neill 2018). With these numbers, our species so controls and dominates the world that biodiversity and how we understand it are tightly linked to human activity.

The current geological age, defined as the period during which human activity has been the dominant influence on climate and the environment, is often called the Anthropocene. Human influence is causing the world and its biodiversity to change rapidly. Despite this, Neo-Malthusian predictions of world collapse due to overpopulation and lack of resources have been wrong over and over again, largely because the power of technological advances was not anticipated (Lempert 2018). Often, it feels we are living in the past and focusing our biodiversity goals on trying to restore some previous state of nature. Instead, perhaps we need to envision a new future. We must ask ourselves how we can embrace technology, modeling, psychology, and communication to anticipate changes and maximize biodiversity for the future.

David L. Pearson

dpearson@asu.edu

1 School of Life Sciences, Arizona State University, Tempe, AZ 85287-4501, USA
First on a list of "must dos" to try to maximize biodiversity in the Anthropocene is to redefine "natural". When I am in Thailand, or with friends in the Cofan, Quichua, and Mayajuna societies of the Amazon, their cultural beliefs insert humans into the community of animals and plants as members of the local ecosystem. But in much of European and American cultures, the definition of "natural" is "not made or caused by humankind." If we perceive ourselves as outside of nature, we are likely to lose the insight of a participant. Until we accept ourselves as a functioning member of nature and not apart from nature, we will likely never have the sophistication to resolve the problems facing biodiversity (Willis and Birks 2006).

In a world of reduced research funding for whole organism studies, we need to integrate our work on biodiversity with that of the growing cadre of citizen scientists (MacPhail et al. 2019). Economists tell us that as societies grow their wealth, we can expect higher school enrollment rates, higher science test scores, lower fertility rates, increased political stability, greater public awareness of the environment, and more leisure time (Leadbeater and Miller 2004). Within a generation in many Asian, African, and South American countries, the children of parents who could barely earn enough for food are now seeking hobbies. Many individuals looking for an avocation have chosen to develop their abilities in nature watching. From marine habitats where millions of amateur shell collectors and scuba club reef photographers investigate sites rarely visited by professionals, to tropical forests where bird enthusiasts and insect collectors visit sites seldom studied by professionals, nonprofessionals have a tremendous potential to help overcome the lack of knowledge of biodiversity throughout the world. Their 
interest levels range from those of occasional observers to serious and committed citizen scientists who function at the level of some professionals but are not paid for their work. Professional scientists in the field of biodiversity can take advantage of this growing data base by learning how to best work with these citizen scientists, engage their interests, provide direction for their energies, and share the credit with them for advances.

In the Anthropocene, scientists cannot rely only on scientific journals and professional symposia to communicate their findings. Communicating with the public, including legislators and other decision makers, will be essential but very different (Richter et al. 2019). Because science is based on skepticism and goals of rejecting ideas, it is often difficult to explain the impact of your research to a public who just wants to know if your discovery will change their lives or not. As scientists we often use the scientific method as an outline for our presentations, but non-scientists are unlikely to pay attention to a list of hypotheses, predictions, and tests long enough to hear when you finally get to the punch line. Start with why your finding matters, rather than the methodology used. Put research in context. Participate in outreach work, talk to nature clubs and service organizations, and contribute to educational websites. But know your audience. The way you deliver scientific information cannot be one size fits all. Recognize and avoid jargon, and use metaphors and analogies so that you are relatable and human.

The Anthropocene will see an increase in mass movements of people from rural areas to urban areas that will alter the direction of many studies of biodiversity. By 2050 some experts estimate that nearly $75 \%$ of the world's population will live in cities ( $\mathrm{Li}$ et al. 2019). Thus, many biodiversity studies will shift from the rapidly disappearing pristine habitats to focus on urban ecology. Although national parks and isolated patches of habitat should not be abandoned, research efforts need to focus on secondary habitats in and around urban areas to conserve as much of the changing biodiversity as we can. Some species appear pre-adapted to do well in cities with only a minimum of critical greenery and habitat. Other species are already adapting to city life through rapid evolution. Exotic and introduced species often become integral parts of the biodiversity (Santangelo et al. 2018). We need to plan to protect this part of the Anthropocene biodiversity through collaborations among city engineers, construction companies, economists, sociologists, politicians, and biologists.

As habitats are developed and degraded for agriculture, mining, housing, and other human use, an increasing proportion of biodiversity will become dependent on the stewardship of indigenous people. In the desert of central and southern Arizona, USA, lies the "Sun Corridor" megapolitan area between the cities of Phoenix and Tucson. Its population is predicted to grow from the present 6 million to perhaps
20 million or more by the year 2050 . In the midst of this belt of development lies 1.5 million $\mathrm{km}^{2}$ of the Gila River Indian Community. Its members are dedicated to preserving their historical culture, land, and biodiversity in the face of this onslaught around them. As another example, in parts of Mexico up to $80 \%$ of the forests are communally held (Bray et al. 2006). This land status of indigenous people is repeated in many other parts of the world, and it warns us to address landscape dynamics and inherent biodiversity in the context of current land tenure systems (Ascanio-Lárraga et al. 2018). Understanding the role that indigenous people play regarding biodiversity conservation becomes relevant not only for academia but also for policy and human livelihoods. Maximization of biodiversity in the Anthropocene will mandate profound apppreciation of local indigenous cultures as well as levels of cooperation and tolerance seldom pursued in the past by the dominant cultures.

Finally, those of us who are professional scientists should work harder to report biodiversity knowledge on which the public and decision-makers can rely with understanding and confidence. This effort will directly inform policy that will maximize biodiversity in the Anthropocene. As an example, powerful legislation, such as the Endangered Species Act (ESA) in the United States or international treaties such as CITES, have proven to be controversial. Often this can be traced to unclear communication of relatively subjective evidence (Maiorano et al. 2019). If the public perceives that these species are chosen inappropriately, the negative economic impact often associated with them will be magnified, and species extinctions could result. Incorporating more quantitative and reliable assessments of rarity, such as detectability measurements, are likely to become the essence of most future endangered species proposals.

The Anthropocene will be filled with rapid changes and full of challenges. Maximizing the biodiversity of the Anthropocene will necessitate many more constructive changes than the few options I have presented here, but at least these are places to start. Instead of looking back to the times of the American Revolutionary War and Civil War to replicate the biodiversity we have lost, we need look to the next 250 years.

\section{Compliance with ethical standards}

Conflict of interest The author declares that he has no conflict of interest

\section{References}

Ascanio-Lárraga JA, León-Cortés JL, Castillo-Santiago MA, RamírezSegura E (2018) Logging pattern and landscape change in Southern Mexico: identifying potential weaknesses and strengthening 
conservation in community-based management programs through landscape analysis. J For 116:539-546. https://doi.org/10.1093/ jofore/fvy045

Bongaarts J, O'Neill BC (2018) Global warming policy: is population left out in the cold? Science 361:650-652. https://doi.org/10.1126/ science.aat 868

Bray DB, Antinori C, Torres-Rojo JM (2006) The Mexican model of community forest management: the role of agrarian policy and entrepreneurial organization. For Policy Econ 8:460-484

Leadbeater C, Miller P (2004) The Pro-Am revolution: how enthusiasts are changing our economy and society. Demos 4:5-74

Lempert D (2018) Futurology needs to focus on measurable variables, causality and social structural models and learn from past mistakes: a response to "A history of possible futures: multipath forecasting of social breakdown, recovery, and resilience. Cliodynamics 9:140-161

Li X, Zhou Y, Eom J, Yu S, Asrar GR (2019) Projecting global urban area growth through 2100 based on historical time series data and future Shared Socioeconomic Pathways. Earths Future 7:351-362. https://doi.org/10.1029/2019EF001152
MacPhail VJ, Richardson LL, Colla SR (2019) Incorporating citizen science, museum specimens, and field work into the assessment of extinction risk of the American Bumble bee (Bombus pensylvanicus De Geer 1773) in Canada. J Insect Conserv 23:597-611

Maiorano L, Chiaverini L, Falco M, Ciucci P (2019) Combining multi-state species distribution models, mortality estimates, and landscape connectivity to model potential species distribution for endangered species in human dominated landscapes. Biol Conserv 237:19-27. DOI:https://doi.org/10.1016/j.biocon.2019.06.014

Richter A, Sieber A, Siebert J, Miczajka-Rußmann VL, Zabel J, Ziegler D, Hecker S, Frigerio D (2019) Storytelling for narrative approaches in citizen science: towards a generalized model. J Sci Commun.https://doi.org/10.22323/2.18060202

Santangelo JS, Rivkin LR, Johnson MTJ (2018) The evolution of city life. Proc R Soc B285:20181529. https://doi.org/10.1098/ rspb.2018.1529

Willis KJ, Birks HJB (2006) What is natural? The need for a long-term perspective in biodiversity conservation. Science 314:1261-1265. https://doi.org/10.1126/science.1122667 